\title{
FIFTY YEARS OF PROGRESS IN ICE ENGINEERING
}

\author{
By LORNE W. GOLD \\ (Institute for Research in Construction, National Research Council of Canada, Ottawa, \\ Ontario K1A 0R6, Canada)
}

\begin{abstract}
The literature reporting scientific and engineering investigations on ice has grown rapidly in the past 50 years, and increased by a factor of at least ten in the past 20 years. A review is presented of advances in engineering for ice problems during this period, including ice formation in rivers, lakes, and oceans; ice forces on structures; bearing capacity of ice covers; and atmospheric icing. The difficulties faced by engineers due to the unique physical and mechanical properties of ice and its normal thermal state are emphasized.
\end{abstract}

\section{INTRODUCTION}

During the past 200 years there have been remarkable advances in engineering. A major area of progress has been on problems caused by cold weather, particularly those caused by ice. As early as the mid-1800s, ice was imposing significant constraints on activities such as the construction and operation of hydro-electric systems and shipping on inland waterways and in coastal regions.

Engineering involves four principal steps. The first is to define the problem and possible solutions to it. Once a possible solution has been determined, the next step is to design in specific terms the structure to be built or the action to be taken. When the design phase has been completed, the structure is built or the desired action initiated. In the final, operational phase, the structure or other solution serves its intended purpose. For a project to be successful, the engineer must have the knowledge, information, and technology that will allow workable and cost-effective decisions to be made for each of the four steps.

It was appreciated early that for problems due to ice, a good knowledge of its properties and effects is required for all four steps. For most problems, the properties of ice are not constant but are subject to the variability of weather, location, and other conditions of its formation. In addition, for many engineering projects it is the extreme condition that the ice might impose that must be determined. As a result, both engineers and scientists have carried out extensive investigations on the properties of ice and on the factors controlling its formation at sites where development is taking place or for situations for which it presents a problem.

Often it is not possible for the engineer to obtain all the information that is desired, particularly concerning extreme events. Appreciable attention has been given, therefore, to determining the principles and physical laws that govern the behaviour of the ice in order to provide a basis for correlating observations and for making engineering estimates or decisions when only a few observations are available. Because of this lack of information, and the variability in the properties of ice, the development of a proper scientific and technical basis for engineering practice has been an important factor in the progress that has been achieved.

In undertaking this review as part of the fiftieth anniversary celebrations of the International Glaciological Society, it seemed appropriate to start by looking at the Journal of Glaciology, published by the Society since 1947. From its first issue until 1979, the Journal had a section called "Glaciological literature", which presented references to papers published in the major subjects of glaciology, including engineering (International Glaciological Society, 1947-79). Since 1979 this section has been incorporated into Recent Polar and Glaciological Literature published by the Scott Polar Research Institute (Scott Polar Research Institute, 1980-86). The references that have been compiled and the papers published in the Journal are a valuable comprehensive record of progress, and lead to other major sources of information. The following sections describe some of the characteristics of ice that make it such a challenge for engineers, and summarize progress during the past 50 years for selected areas of engineering. These summaries are based almost entirely on the references in the Journal of Glaciology and in Recent Polar and Glaciological Literature.

\section{ICE AS A MATERIAL}

Ice is normally at a temperature within $50^{\circ} \mathrm{C}$ of that at which it melts. Its homologous temperature (i.e. the ratio of its temperature to that at which it melts, in ${ }^{\circ} \mathrm{K}$ ) is usually greater than 0.80 . From a materials point of view, it is in a high-temperature state. Its properties and behaviour have the sensitivity to temperature and stress that can be expected of a material in this thermal condition. Engineers rarely have to work with a material that is normally at a temperature so close to its melting point.

The density of ice is less than that of water. Not only has this allowed life to evolve on Earth, it has had great consequences for engineering. Ice presents problems but it also provides possibilities for water to be utilized during winter.

Ice is a crystalline substance. The resistance of the ice single crystal to deformation is much less in certain crystallographic directions than in others. It deforms under a shear stress much like a deck of cards.

Ice deposits are usually polycrystalline. They vary in size from very small to several thousand square kilometres in extent. Deposits may be granular or columnar grained, depending on the conditions of formation.

Ice does not easily incorporate impurities into its crystalline structure. During freezing of water, the impurities may occur as inclusions at the boundaries between relatively pure ice grains or sub-grains. The result of this process is most apparent in sea ice. Because of the variety of grain textures and the effects of impurities, there is a wide variety of naturally occurring ice types. This must be appreciated when developing solutions to many engineering problems.

The crystallographic anisotropy of ice, coupled with the range in grain-size and structure, results in a wide variation in the response of polycrystalline ice to loads. For a given ice body, the response ranges from ductile to brittle, depending on temperature and state of stress.

Most of the physical properties of ice were known with sufficient accuracy for engineering purposes in 1936. A good summary of these properties was published 4 years later (Dorsey, 1940). Its deformation behaviour and strength were not so well known, and there was a large unexplained scatter in measurements due to lack of understanding and control of all factors that affect these properties. 
Considerable attention has been given to the deformation behaviour and strength of ice because of engineering interests. This work is defining the dependence of the strength and the elastic, time-dependent, and permanent components of the deformation on temperature, grain structure and size, stress, strain-rate, and other variables (Ashton, 1986). Most of it has been for the uniaxial state of stress and "fresh-water" ice, but increasing attention is being given to the biaxial and triaxial states of stress and to sea ice. Measurements of the mechanical properties of both fresh-water and sea-water ice have shown that great care must be taken, as would be expected for any material in a high-temperature state, in preparing specimens; determining their grain structure, density, and impurity content; applying loads; controlling and measuring stress and strain-rate; controlling temperature; and taking into account the relative stiffness of the ice and testing frame, in order to obtain consistent results.

\section{ICE FORMATION IN RIVERS AND CHANNELS}

The development of hydropower and growth of shipping on inland waterways stimulated in cold regions an increasing interest in the occurrence of ice and the formation of ice covers. Information such as date of freezeup, date of break-up, and occurrence of major ice events began to be recorded at an early date. Instrumentation became available for the measurement of meteorological variables and water conditions. Concurrent with the practical needs for information, physicists and other scientists began to study the processes of ice formation and to seek the laws of Nature that governed them. By 1936 there was a good qualitative understanding of the dependence of the formation of ice and of ice covers on weather and water conditions (Barnes, 1928). There was an appreciation of the information on ice required by engineers for the design, construction, and operation of hydropower, flood control, ice management, and inland navigation systems, and there was a recognized need to improve the basis for the selection and design of preventive and protection measures and to predict the consequences of such actions.

Figure 1 presents the number of papers published in this general subject area from 1936 to the present, as

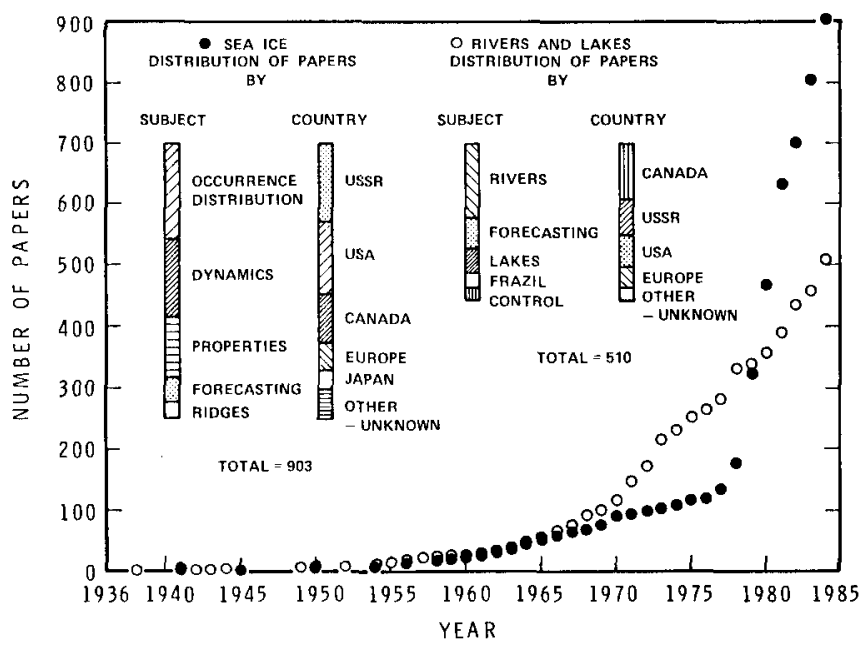

Fig. 1. The growth in the number of papers relevant to engineering needs on river and lake ice and on sea ice, listed in Glaciological literature and Recent Polar and Glaciological Literature (International Glaciological Society, 1947-79; Scott Polar Research Institute, 1980-86).

identified in the Journal of Glaciology and in Recent Polar and Glaciological Literature. Also shown in the figure are the relative contributions of the principal countries that participated in this work and the proportion of the papers concerned with the principal topics. Up to about 1960 , most of these papers were qualitative, reporting observations on the development and deterioration of ice covers under various river, lake, and reservoir conditions; on the formation of frazil ice, anchor ice, ice jams, and ice dams; and on the performance of engineered works and their effect on the ice regime. Theoretical work was progressing on the dependence of water temperature on environmental factors and on the hydraulics of rivers and channels under winter conditions. The base was being set for the evolution of a new discipline.

By 1959, activity had grown to a level to justify the International Association of Hydraulic Research (IAHR) in holding a seminar on ice problems and forming a Committee on Ice Problems at its biennial congress in Montreal. This was followed by similar seminars at its 1965 and 1967 congresses, and the initiation in 1970 of a series of symposia held every 2-3 years. The proceedings of these seminars provide an excellent record of progress in this area of ice engineering (International Association for Hydraulic Research, 1959-86). At the meeting in 1967, work was begun on a glossary for river and lake ice (Starosolszky, 1977).

By 1959 , field observations were beginning to show the dependence of the ice-forming processes in rivers and channels on the Froude number, a basic parameter in the theory of hydraulic flow. Once the significance of the Froude number was recognized, it was possible to explore mathematically the dependence of the processes on the rate of flow of the water, the characteristics of the river or channel, and the properties of the ice. The extension of hydraulic modelling to include the ice-affected condition progressed relatively rapidly.

The development of theory, analytical procedures, and modelling capability, combined with field observations of performance, steadily improved the engineer's ability to make decisions on how to minimize ice problems and to predict the consequences of those decisions. This progress also defined more rationally the site measurements that were required at the pre-design stage and how to evaluate the performance of completed works. The result of this interaction between engineering need and scientific challenge is shown in Figure 1 by the marked increase in publications since the early 1960s.

There have been many theoretical and laboratory flume simulations during the past 30 years of the formation and progression of ice covers for rivers, but very few field measurements. The reason for this is that such measurements are costly and usually dangerous to make. Results of observations on the processes of ice-cover formation for three major Canadian rivers are presented in Figure 2 in a plot of velocity of flow and thickness of ice cover (Michel, 1984). They indicate the progress that is being made in the understanding of this complicated, natural phenomenon.

The development and application of ice-control methods and ice-management practice have benefited significantly from this increased understanding. This includes electrical heating and mechanical systems for ice prevention and removal, the use of icebreakers for breaking up ice formations, the use of air bubblers for preventing ice formation, the development of devices for passing ice over or around hydraulic structures, the use of ice booms for stabilizing ice covers, and channel modifications and regulation of flow to alleviate ice problems.

Because of the dynamic nature of the ice-forming processes and the difficulty of measuring important variables at critical times such as at the onset of instability, it is difficult to verify theory describing the formation of ice for rivers and channels. This situation is not unusual for engineering and a scientifically satisfying resolution of it may not be required. Over the years, a number of methods for solving or ameliorating ice problems have been identified. Theory, analytical procedures, modelling, and experience provide a reasonable basis for the decisions that must be made concerning their use. Measurement techniques and observational procedures required for optimization and control of constructed systems are well established and understood. These observations and measurements also provide a basis for checking the accuracy of theoretical, analytical, and modelling predictions, and thereby the validity of these methods. The value of these records for this purpose increases with the years over which they are 


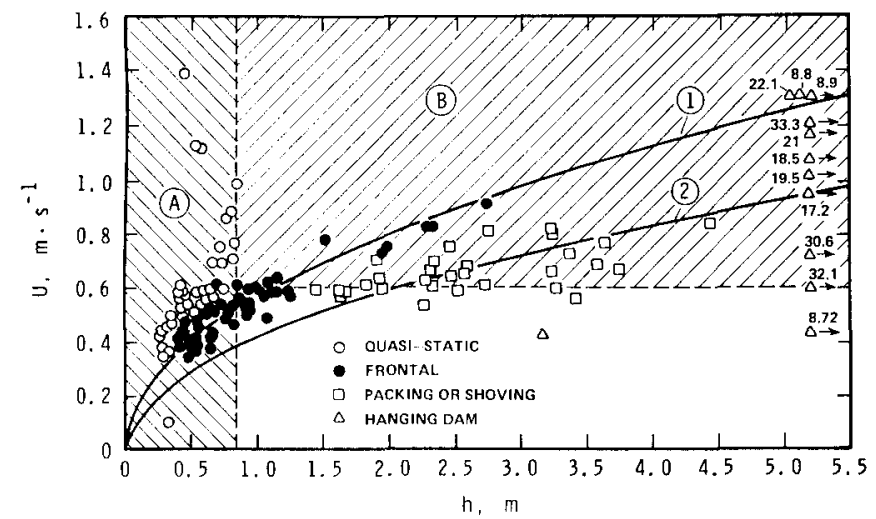

Fig. 2. Dependence of the ice-cover formation processes on the velocity of flow of the water, $U$, and the thickness of the ice, $h$ (from Michel, 1984).

o The quasi-static accumulation and freezing together of ice flows; - Progression of the cover up-stream by the addition of floes; the cover is often more than one layer thick. $\square$ Observed conditions of instability of the leading edge of the ice cover, or the full cover, resulting in packing and shoving until a new thickness is attained that is appropriate for the imposed mechanical and hydraulic forces. $\Delta$ Observed conditions of transport of ice beneath the cover and the formation of hanging dams. (1) Best fit of theory to ice-cover formation by frontal progression; Froude No. $=0.18$. (2) Best fit of theory to observations of packing and shoving; Froude No. $=0.13$. (A) Range of conditions for the quasi-static accumulation of ice floes. (B) Range of conditions for the formation of hanging dams.

maintained. In this way, continuous improvement is made in engineering practice that is essentially empirical but is founded on a growing understanding of the processes involved and on steadily improving theoretical and analytical methods. The benefits that are obtained through this feed-back between engineering practice and scientific study are brought out most clearly in the proceedings of the ice symposia of the IAHR.

\section{SEA ICE}

Figure 1 presents the output of publications on the formation and dynamics of sea ice. To 1960, the papers were concerned primarily with observations of freeze-up, break-up, ice distribution, and weather elements and other variables upon which the ice conditions depended. Most of these observations were for navigable, near-shore regions, and the Arctic.

About 1960 interest began to grow in the dynamics of sea-ice covers and the dependence of the motion of the covers on water currents and weather. This growth was partly in response to the need for a better understanding of the role of the Arctic in global weather and ocean systems. Work was initiated on models to describe the dynamic processes associated with the evolution and deformation of seaice covers, e.g. the Arctic Ice Dynamics Joint Experiment (Arctic Ice Dynamics Joint Experiment, 1970-78). Observations on sea ice for both navigational and scientific purposes were greatly aided by developments in remote sensing from aircraft and subsequently from satellites.

Through the 1960s there was a growing interest in the resource potential of the north, which was greatly accelerated by the oil crisis in the early 1970s. By 1976, the interests of the petroleum industry in potential oil and gas fields under ice-affected waters began to be reflected in the literature. The industry had major problems to solve in the development of the exploration and production methods for this challenging environment. It was necessary to determine normal and extreme ice conditions for design and operational decisions, and to establish the effects of these conditions and how to measure them. There was a marked increase in investigations of the dynamic behaviour, structural properties, and distribution of sea-ice covers, as is clearly evident in Figure 1. The interests of the engineer and the scientist coincided. Scientists expert on ice were recruited for engineering studies; companies established highly capable groups to carry out these studies and related research.

It was recognized that ridges and rubble fields would probably cause the most severe load for many offshore structures. They were already recognized as a major impediment for shipping. Several investigations were carried out on the dimensions and structure of such bodies and on their spatial distribution. These observations were made on and under the ice, and from ships, aircraft, and satellites, using photography, radar, lasers, and other remote-sensing tools.

The mechanisms of formation of ridges and rubble fields are now reasonably well known and analytical models have been developed to describe them. Estimates have been made of the compressive stress that occurs during their development, and some measurements have been made. The maximum value is about $500 \mathrm{kPa}$. This is probably about the upper limit for stress in the Arctic ice pack.

Attention is now being given to the effective strength of ridges and rubble fields, which must be known to assess the force that they might impose on a structure or their resistance to the passage of ships. Attempts are being made to model these features in the laboratory but it may be impossible to achieve completely satisfactory simulations because of incompatibility in the scaling laws. Engineers will probably have to wait for measurements of forces during the collision of such features with full-size structures to confirm the validity of their models and analytical procedures.

\section{ICEBERGS}

Until recently, most observations on icebergs had been concerned with the hazard they pose for ships. Some studies have been made of them as part of the geological processes that shape the surface of the Earth, and because they are such a spectacular natural phenomenon. Their interest to the engineer increased greatly in the 1970 s when they were recognized as a potential major load for offshore structures, particularly in the Grand Banks area off the east coast of Canada.

The International Iceberg Patrol was begun in the early 1900 s to provide forecasts of icebergs for ships travelling through regions affected by them. Initially, most observations were made from ships. Beginning about the late 1940s, increasing use was made of aircraft. Capability for detecting and tracking icebergs has steadily improved with advances in remote-sensing technology for ships, aircraft, and satellites, and is probably adequate now from the engineering point of view for offshore structures.

The engineer has three choices for a structure in the path of an iceberg: the structure can be moved, the iceberg can be moved, or the structure can be built strong enough to withstand a collision with it. Moving out of the path of an iceberg is currently done for structures used in exploration for oil and gas. This is probably impractical for the structures required for production. Methods have been developed for towing icebergs and their limitations have been identified. Consideration is being given to methods of breaking up icebergs, including explosives and thermal shock by rapid heating.

Several studies have been carried out on the shape, size, distribution, and frequency of icebergs (Howard, 1986). These studies provide necessary information for decisions concerning the feasibility and design of fixed structures that must withstand collisions. Icebergs are being instrumented for studies of their dynamic behaviour, including their response to waves, wind, and ocean currents. This information is particularly important for the development of strategies for iceberg avoidance and for analytical and theoretical models of their behaviour.

Scour marks and pits caused by icebergs striking the ocean floor indicate the threat they pose for pipelines, well heads, and other sub-sea structures (Goodwin and others, 1985). Methods have been developed to survey these features, and information is being assembled on their frequency, age, depth, and length. Model studies and 
theoretical considerations are being coupled with field observations to describe the interaction between icebergs and the sea floor. These studies are bringing out the dependence of scour and other types of interaction on the effective strength of the sea-bed surface deposits, the shape and energy of the iceberg, the strength of the ice, and the dynamic forces imposed by waves, wind, and ocean currents.

The shortage of fresh water in some parts of the world has resulted in attention being given to satisfying this need by icebergs. Appreciable information has been assembled on the rate of deterioration of icebergs in sea-water, the problems of guiding to a desired destination, and the methods of using them as a fresh-water source after delivery (International Glaciological Society, 1980). Most of the attention has been directed to the large tabular icebergs produced in the Antarctic. Results of these investigations indicate that this source of fresh water is not very promising, particularly for countries in the low latitudes, such as the Middle East.

\section{NAVIGATION AND ICEBREAKERS}

For navigation in ice-affected waters, the engineer is concerned primarily with the design, construction, and operation of ships and harbours, and the development of inland and coastal water routes. Progress in this work is recorded in the proceedings of the Permanent International Association of Navigation Congresses (PIANC) and the ice symposia of IAHR. In addition, by the 1970s interest and activity had reached the level to cause the initiation of a biennial series of symposia on Port and Ocean Engineering under Arctic Conditions (POAC, 1971-85). The meetings of these three international associations record the considerable advances that have been made in extending the navigation season into the winter through proper design and use of icebreakers and ice-control and prevention systems. One challenge has been to optimize the dual use of inland systems for navigation and power-generation purposes.

Until the 1950s, icebreaker technology was relatively simple, based largely on experience. The desire to extend the winter navigation season in areas such as the Baltic Sea and the Arctic coast of the U.S.S.R. caused increasing attention to be paid to the design of icebreakers and the mechanisms of ice-breaking. Great progress has been made in the past 25 years in the ability to model ice conditions. Special "ices" have been developed whose strength can be controlled so as to satisfy more closely the requirements of scaling. It is now possible to simulate in the laboratory ice features such as ridges and rubble fields, and conditions such as broken ice.

Development of modelling and analytical methods for ships has a major advantage over that for fixed structures. Ships operate regularly in ice; for a fixed structure, it is necessary to wait for the ice to come to it. It is easier to obtain for ships, therefore, the information on ice forces and performance required to calibrate and validate modelling and analytical procedures. Methods of instrumenting ships for these measurements are now highly advanced, and there is good ability to determine the properties of the ice. The benefits from this work can be seen in improved hull forms, better propulsion systems, and development of methods to reduce friction between the ice and the ship. Coupled with improved performance of the ships in ice has been an appreciable increase in the skill with which the vessels are used for particular tasks and ice conditions. Year-round operations in some ice-affected areas are now routine because of this ice-breaking ability.

To date, the emphasis has been on the development of an understanding of the ice-breaking process. In the future, greater attention will probably be given to optimizing performance and to the development of an ice-breaking capability for ships designed for specific purposes, such as tugs, tankers, and dredgers, so that they can operate without icebreaker support. One of the challenges will be to design a hull system that will allow the vessel to operate efficiently in both ice-covered and open waters.

\section{ICE FORCES}

A major challenge for the engineer is to determine how strong a structure must be to resist forces that may be imposed on it by floating ice. For some situations, the ice may not be able to move relative to a structure by an amount and at a time to cause a serious load. This is difficult to predict, however, and normally the engineer must ensure that if a serious load develops, it is the ice that yields or fails, not the structure. It was natural, therefore, for measurements to be made of the strength of ice as early as the late 1800 s.

The principal modes of failure of ice at structures are crushing, splitting, bending, and buckling. It was soon appreciated from the estimated strength of relatively large structures that were regularly subjected to ice loads, such as bridge piers, wharfs, and dams, that the average stress in the ice at the time of failure must be appreciably less than that measured in the laboratory. By the 1930s, empirically justified design loads were being used and studies were being carried out to determine the reasons for the difference between the apparent strength at failure and that determined in the laboratory.

Extensive work was done in the U.S.S.R. These investigations resulted in the preparation of "Technical specifications for determining ice loads on river structures" published in 1959. Revisions were published in 1962, 1976, and 1983 (Gosudarstvennyy Komitet Soveta Ministrov SSSR imposed on a structure is estimated by an equation of the form

$$
P=M R \mathrm{e}^{b h}
$$

where $M$ is a coefficient that depends on the shape of the structure; $R_{\mathrm{e}}$ is the "standard strength" of the ice, determined from test and experience, and whose value depends on temperature and, for the strength in bending, on the width of the structure and thickness of the ice; $b$ is the width of the structure; and $h$ is the thickness of the ice.

A similar evolution in practice has occurred in North America. Prior to 1947 , a constant crushing strength for ice of $2.76 \mathrm{MPa}$ was recommended for the design of bridges and piers, even though experience indicated that this was too severe in most cases and lower effective strengths were used in practice. A bridge code was published in Canada in 1978 which allowed the engineer to select a failure strength in the range of $0.70-2.80 \mathrm{MPa}$, depending on the ice conditions where the structure was to be built (Canadian Standards Association, 1978). This strength is modified by a factor that depends on the ratio of the width of the pier to the thickness of the ice. The U.S.S.R. and Canadian codes give about the same total load for similar situations.

For long structures, such as dams, design loads are in the range of $1.4 \times 10^{5}$ to $2.8 \times 10^{5} \mathrm{~N} / \mathrm{m}$. These loads, which are less than would be estimated from the strength of ice measured in the laboratory, are based to a large extent on experience.

It was recognized that the maximum load would be reduced if the ice was forced to fail by bending. Structures with sloping faces are built to induce this mode of failure. The dependence of the reduction in load on slope angle has been investigated analytically and by laboratory modelling. Load reductions allowed by this method are given, for example, in the U.S.S.R. and Canadian codes. Measurements of loads on structures are needed, however, to validate expressions for estimating design loads for both sloping and vertical-faced structures.

Dynamic ice loads induce vibrations and some structures have failed under this condition. Analytical and model studies have been carried out on this problem and measurements made on structures subject to dynamic loads. This work has shown that the frequency of vibration depends on the dynamic characteristics of both the structure and the ice cover, but the nature of the interaction is not yet fully understood. Although instructions are given in codes on the design for dynamic loads, additional measurements on structures are required to confirm recommended practice and the results of analytical and model studies.

Consideration has been given to loads resulting from 
temperature changes imposed on the ice. The mechanisms by which these loads develop are not fully understood, and it is not possible to calculate with confidence the maximum stress that may occur under given conditions. Measurements indicate that the maximum thermal stress for an extended ice cover is about $0.5 \mathrm{MPa}$. It appears to be limited by the creep induced by the stress and by the tendency for the ice cover to buckle.

The interests of the petroleum industry to explore for oil and gas in ice-affected regions greatly increased the need for information on ice forces. Structures would have to be built to stand up to severe ice conditions for which there was no previous information. Studies were initiated to define these conditions. Conceptual designs for exploratory and production platforms began to appear that included cylindrical, conical, and caisson-retained structures, built-up islands, and structures founded on the ocean floor, or semisubmersible and anchored. Analytical and model studies were carried out on the interaction between ice and structures, and the factors that affect this interaction. Considerable attention was given to the development of modelling techniques, including the scaling laws and the material used to simulate ice, in order to increase confidence in the loads predicted by this method.

Industry has developed considerable experience through the construction and use of built-up islands for exploratory drilling in the shallow waters of the Beaufort Sea and the North Slope of Alaska. These islands have been in shore-fast ice, and the movement of the ice cover relative to the structure has been small. More recently, prefabricated structures have been placed in deeper waters. Some of the structures have been exposed to the continual motion of the Arctic pack ice. Observations have been made on imposed forces and the nature of the interaction between the ice and the structures.

Figure 3 presents information on the measured or estimated average stress in a continuous ice cover when failing against a vertical structure of width $b$. The average

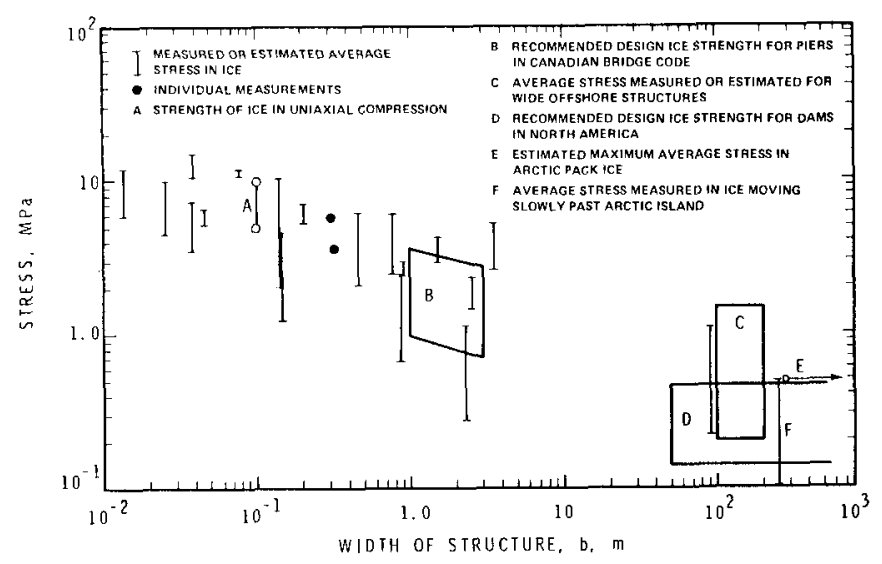

Fig. 3. Observed, estimated, and recommended average stresses in a continuous ice cover failing against a vertical structure of width $b$.

stress is defined as the total force on the structure divided by the width of the structure and the thickness of the ice. Clearly, there appears to be a decrease in the apparent strength of the ice with increase in the width of the structure. Included with the observations are the range in ice strengths recommended for bridge piers and dams. Shown also is the estimated maximum compressive stress in the Arctic pack ice, results of measurements of the stress in ice moving slowly past an island in Lancaster Sound, and the range in the compressive strength observed for ice subject to simple compression. It can be seen that the design loads determined empirically for bridge piers and dams are not out of line with the dependence of average stress on width of structure that appears to be emerging for continuous ice covers.

Theory and observation suggest some interesting reasons for this dependence. For structures less than $1 \mathrm{~m}$ wide, the thickness of the ice would be of the same magnitude or greater. There would be a significant confining effect, and one would expect the maximum average stress to be greater than the strength measured in simple compression. For structures of width up to $5 \mathrm{~m}$ and relatively thick ice, crushing is the principal mode of failure. There is evidence for this mode that the crushing strength decreases with increase in the area over which the failure occurs. As the width of the structure increases, the mode of failure can change to splitting or buckling. For structures sufficiently wide, failure does not usually occur over the full width at the same time. The problem of non-simultaneous failure has not yet been adequately resolved, but one would expect that the effective average stress would decrease with increasing width of the structure.

Figure 3 has been presented simply to illustrate the nature of the information that is being accumulated and the order that appears to be present for at least one type of interaction of ice with a structure. Similar information must be assembled for events such as collision with an iceberg, ridge, or hummock field, to determine which will cause the more serious load and, therefore, govern the design.

A problem that has received considerable attention is the force that can be imposed by ice on structures due to a change in water level. Interest has been directed, in particular, to the shear strength of the bond between ice and the structure. This problem is addressed in both the U.S.S.R. and Canadian codes. A particular exampie of this problem is the build-up of ice formations due to tidal effects. The loads imposed by these formations have caused failures and must be taken into consideration in design. If the tidal change is sufficiently large to cause cracks to open, the cracks can fill with water, which subsequently freezes. The tidal cycle can then cause a continuous jacking action that forces the ice away from the structure, and the structure must be sufficiently strong to withstand the resulting local and total loads. This process can also be caused by fluctuating river levels, and has been observed to displace bridge piers.

Progress during the past 50 years in ability to estimate forces due to ice has been impressive. Methods of measuring forces on structures are well developed and some good results have been obtained. Most of the measurements of local and total ice loads on large offshore structures, however, are proprietary and so are not available for evaluation by the engineering community. The dependence of the load distribution through the ice cover on temperature and type of ice, and the effect of the distribution on how the ice fails, have not been properly addressed. Much is still to be done to ensure that structures exposed to severe ice conditions will be safe and perform as desired.

\section{BEARING CAPACITY}

Ice covers have been used to cross water bodies since the time of early Man. The maximum load that can be placed safely on ice of given thickness has been determined primarily through experience. Military operations provided the basis for what appears to be the earliest published advice on the thickness of ice required to support a given load (Dorsey, 1940). During the past 50 years much additional experience has been recorded. This experience is guiding the development of engineering procedures for the design and operation of floating ice crossings and ice platforms.

Observations have shown that for moving loads it is reasonable to assume that an ice cover behaves as an elastic plate on an elastic foundation. For relatively low speeds, the deflection of the ice cover under load is essentially the same as that for the static elastic case. If a load $P$ acts over an effective area of radius $a$ on competent ice of thickness $h$ and effective tensile strength $R_{\mathrm{e}}$, the relation between allowable load and ice thickness is of the form

$$
P=B(b) R \mathrm{e}^{h^{2}}
$$

where $b=a / l ; l$ is a "characteristic length" that depends on the elastic properties of the ice and the thickness, $h . B$ is 
relatively insensitive to changes in $b$. For ice covers of thickness greater than $0.60 \mathrm{~m}$ and effective area of loading of radius up to $2.5 \mathrm{~m}$, it lies in the range of $0.4-0.7$. For the range of ice thickness and effective area of loading for moving vehicles, its value is about 0.6 .

In view of the natural variability in the properties of ice covers, in the temperature, and in the effective area of loading, it has been found appropriate in the correlation of observations of failure and successful performance of ice covers to assume that $P=A h^{2}$. Observations of successful performance for ice covers on lakes and rivers have shown that loads are usually in the range of $P=3.5 \times 10^{4} h^{2}$ to $17.5 \times 10^{4} h^{2} \mathrm{~kg}$, for $h$ in m. $P=17.5 \times 10^{4} h^{2}$ is an upper limit for situations for which risk is acceptable (e.g. tanks in wartime). The usual recommended upper limit for controlled conditions is about $P=7.0 \times 10^{4} h^{2}$. For uncontrolled situations, recorded experience indicates that the loads should be less than $P=3.5 \times 10^{4} h^{2}$ but, even at that level, failures can occur because of imperfections in the cover.

When a vehicle travels on ice covers, a hydrodynamic wave is induced in the underlying water. The wave travels with a speed that depends on the depth of the water and the thickness and effective modulus of elasticity of the ice Reports of failures have indicated that speed has been a contributing factor in some cases. If the speed of the vehicle coincides with that of the wave, the deflection due to the load augments that due to the wave and a serious stress condition can result. Observations for moving loads show that the deflection at the critical speed is $2-2 \frac{1}{2}$ times greater than for the static case. Deviation from the static situation becomes significant at a speed of about 0.7 that of the critical value.

The engineering basis for the design of ice platforms to support stationary loads is not in as good a state as for moving loads and ice bridges. The reason for this is the incomplete understanding of the time- and temperaturedependence of the deformation behaviour of ice for the biaxial stress condition, and the associated redistribution in stress that must occur within the ice cover.

The appropriate criterion for the design of ice platforms to support stationary loads is probably one of performance based on allowable deflection or deflection rate rather than allowable stress. In general, if ice is to support material that must be retrieved or activity such as drilling, there are practical reasons for keeping the deflection less than the freeboard, i.e. the amount by which the ice surface is higher than the free water surface. If the deflection is kept within that limit, the maximum strain induced in ice covers of thickness up to $2 \mathrm{~m}$ is less than $1 \%$ which, for ice, is a relatively small strain.

The implications of this for engineering design have not been fully exploited. For example, static ice loads are usually placed on ice covers for periods of $1-100 \mathrm{~d}$. If the maximum deflection is limited to the freeboard, this period of loading corresponds to a range in average strain-rate of about $5 \times 10^{-9}$ to $5 \times 10^{-11} \mathrm{~s}^{-1}$. This range in strain-rate would be associated with a maximum stress of less than $350 \mathrm{kPa}$. Limiting the deflection to the freeboard, therefore, ensures that the maximum stress remains at a safe level.

The techniques of constructing ice bridges and platforms are now well established. Such structures, built and operated according to experience-based instructions, are used routinely for the support and transport of heavy loads, particularly in remote regions. Their design will probably remain empirical because of the variability in material and conditions that occur in practice. Better knowledge of the dependence of the strain-rate and strength of the various ice types on temperature and time for the biaxial stress conditions that are imposed is required, however, to provide greater certainty concerning the level of safety and to extend current practice to new situations.

\section{ICING (Minsk, 1983)}

The development of the aircraft was a major incentive for the study of ice formation on objects and ways to control or prevent it. Work on aircraft icing was initiated in the 1930s and was particularly active from about 1940 to 1960. A good appreciation was developed of the physics of the ice-accretion process and the characteristics of natural environments associated with it.

Considerable work has been carried out in the laboratory and under natural icing conditions on the icing of simple objects such as spheres and cylinders. Much of the understanding of the process and the development of theory is based on this activity. These studies have shown that the principal factors affecting rate of ice accretion are: air temperature, atmospheric water content, number and size distribution of droplets, wind velocity, shape and size of object on which ice is accreting, velocity of droplet relative to the object, and time taken for freezing to occur.

Accretions of ice occur in two forms: glaze and rime. As the combination of temperature and water flux increases, the density of rime increases from as $10 \mathrm{w}$ as $0.01 \mathrm{Mg} / \mathrm{m}^{3}$ for soft rime to a value greater than $0.6 \mathrm{Mg} / \mathrm{m}^{3}$ for hard rime. For the more severe conditions, the properties of rime begin to merge with those of glaze.

Hot-gas, electrical, and mechanical systems were developed for aircraft for preventing icing or removing accreted ice. They tended to be heavy and to require significant power. Their development was largely empirical, guided by the theoretical and laboratory studies. Considerable use was made of icing wind tunnels. Interest in this work dropped with the introduction of jet-powered aircraft that normally flew above the weather conditions that caused icing.

The development of electronic systems since 1960 has made all-weather flying possible even for light aircraft. In addition, there has been a growing requirement for iceprevention and de-icing systems for helicopters. This has brought about a renewed interest in aircraft icing. Particular attention is being given to modelling the accretion process using the computer, and to heat transfer at unusually shaped surfaces.

Icing is a dynamic process. The shape of the accreting surface, which has a significant influence on both the aerodynamic and thermodynamic aspects of the process, changes continually with time. Numerical modelling appears promising as a method of following the time-dependence of accretion for given icing conditions and structural shapes.

Icing of fixed structures is a particular challenge to the engineer. One of the first tasks in addressing this challenge is to define the extreme icing condition to which the structure will be exposed. In recent years, meteorological networks in some countries have been reporting occurrence and amounts of freezing precipitation. Instruments have been developed to measure the severity of or potential for ice accretion. Little has been done, however, to correlate these observations with the amount of ice that can be expected to form on a given structure or structural shape.

Normally, it is too expensive to incorporate ice prevention or removal devices into structures, and so they must be designed to carry the estimated maximum load. Theoretical and laboratory studies have indicated the dependence of accretion on shape and size, and these factors can be chosen to minimize the effects of ice. Considerable attention has been given to icing of powertransmission cables and means for its control.

An additional problem for coastal and offshore structures is icing due to sea spray. The dependence of seaspray icing on temperature and wind speed is being investigated. Increased attention has been given in the past 15 years to ice formation on ships.

Studies have been made of ice-prevention and removal systems, e.g. ice-phobic coatings, deformable surfaces, heating devices, de-icing fluids, and pneumatic systems. No completely effective control or removal system has been found, and often it is necessary to remove ice using axes and similar mechanical means.

\section{MECHANICS OF FROZEN GROUND}

The ice content of soils at temperatures below $0^{\circ} \mathrm{C}$ can vary from zero to more than $90 \%$; their response to loads ranges from soil-like to ice-like. It is appropriate to mention briefly in this review progress that has been made in engineering for soils in this thermal state because of the major effect of ice on their properties and deformation 
behaviour. Investigations have fallen naturally into two major themes: those on seasonally frozen ground and those on perennially frozen ground, more commonly called permafrost.

Observations on ice in the ground and on frost action, the term applied to processes that occur in soils during freezing, were recorded as early as 1700. In the early $1900 \mathrm{~s}$, it was recognized that, during the freezing of finegrained soils, water may flow to the region of freezing and result in expansion or "frost heaving". This increase in volume was caused primarily by the formation of discrete ice bodies, a process called ice segregation, rather than by the expansion of water on freezing. The principal characteristics of the frost-heaving process were known by the 1930 s, and an empirical rule for the selection of non-frostheaving soils for railway and road sub-grades and for foundations that would be subjected to below freezing temperatures had been specified (Beskow, 1935).

Extensive research since that time has provided a good understanding of the dependence of frost action, and the forces that it may induce, on factors such as soil type, grain-size distribution, temperature, rate of freezing, and availability of water. Theoretical and empirical methods have been developed to predict the occurrence and consequences of frost action, and they have been integrated into design procedures. Techniques have also been developed to use controlled ground freezing to stabilize soil during sub-surface excavations. Considerable attention has been given to conditions that are induced in the vicinity of underground chambers for storage of cryogenic liquids, and by pipelines used to transport gases and liquids at temperatures below $0^{\circ} \mathrm{C}$. Progress in research and engineering for frozen soils is periodically summarized at meetings such as the International Symposium on Ground Freezing held about every second year since 1978 (Jessberger, 1979; International Symposium on Ground Freezing, 1980-81, 1982; Kinosita and Fukuda, 1985).

Permafrost occurs extensively in northern Europe, Asia, and North America, and in the southern mountainous regions of these land masses. The nature of the ice within it can range from microscopic, uniformly distributed particles to very large monolithic bodies. Investigations on the characteristics and origin of this permanently frozen ground were started well before the $1900 \mathrm{~s}$, but the term permafrost was not introduced until about 1945 (Brown, 1970). By the $1950 \mathrm{~s}$ it was appreciated that polar permafrost could be divided into two major zones: discontinuous and continuous. The southern boundary of the permafrost region is defined approximately by the $-1{ }^{\circ} \mathrm{C}$ mean annual air-temperature isotherm. In the discontinuous zone, permafrost occurs in discrete islands which increase northward in thickness and areal extent. Permafrost in the continuous zone is found essentially everywhere under the land surface and increases in thickness northward, attaining depths in excess of $500 \mathrm{~m}$ at some Arctic locations. Each summer the surface of the ground thaws to form the "active layer", the thickness of which decreases northward. The occurrence and depth of permafrost and thickness of the active layer are determined primarily by the climate and surface conditions, such as vegetation, presence of water, and annual average depth of snow cover.

Permafrost frequently contains a great deal of ice but it can be a satisfactory base for engineered works if it remains frozen. Its thermal state, however, is sensitive to changes in conditions at the surface. Such changes may induce melting of the ice with subsequent settlement and loss of support. The choice for most engineered structures to be placed on soils containing ice is either to remove the permafrost before construction or to build in a manner that will maintain the frozen condition or will allow adjustments to compensate for settlements due to thawing.

Growth of centres of population in the Arctic and the desire to develop northern resources, particularly in the U.S.S.R., Alaska, and Canada, have made it necessary to determine proper ways to build and to work on permafrost. As a result of this need, field investigations, and laboratory and theoretical studies have been carried out to establish ways to delineate permafrost, to determine ground temperature and ice content, and to predict the ground thermal regime that will result from changes in surface conditions.
Suitable methods to build foundations such as pile systems for buildings, or to determine the thickness of fills needed to prevent thawing of permafrost under roads, airstrips, or other engineered structures, have been developed. This work has provided the basis for construction codes and technical manuals (SNiP 76, 1977; Johnston, 1981; Fish, 1982).

It is not always possible for the engineer to state with confidence whether a selected solution to a problem will be satisfactory, as the ability to predict the effects that the work will have on the integrity of the permafrost is still not adequate. Because of the number of variables involved, one of the better ways to obtain this knowledge is to monitor the performance of completed works. The correct interpretation of these observations requires a good understanding of the properties of permafrost and how they depend on the factors that control them.

The interest in and challenges of permafrost have resulted in a relatively large international body of scientists and engineers devoted to its study. Their investigations cover several disciplines including geography, geology, geophysics, physics, chemistry, geotechnique, and civil engineering. Work of this multi-disciplinary community is summarized in the Proceedings of the International Permafrost Conferences (International Permafrost Conference, 1963, 1973, 1978-79, 1984; Sanger, 1978). The organization of these conferences will now be an important activity of the recently formed International Permafrost Association.

\section{CONCLUDING REMARKS}

Space does not permit a full coverage of the progress that has been made during the past 50 years in engineering for ice problems. This review would not be complete, however, without a mention of some of the topics that have not been covered. Resource development and other forms of economic, recreational, and scientific activity have taken place adjacent to, under, and in glaciers and the ice sheets of Greenland and Antarctica. In addition to problems associated with this development, engineers have had to consider the consequences of glacier surges and ice avalanches, and the integrity and safety of glacier-dammed lakes. Results of theoretical and field research in glacier mechanics have been applied to these problems.

Extensive investigations have been carried out on the electrical and seismic properties of ice. Much of this work has been in support of remote-sensing techniques for determining the characteristics of ice covers and major ice bodies.

Considerable attention has been given to heat transfer between water and ice, and air and ice (Institut International du Froid, 1920-86). Results of this work are applicable to problems such as ice formation in piped water systems, melting rate for icebergs, design of desalination systems, and performance of heat exchangers for cold-storage plants and air-conditioning systems. The possibility of using large masses of ice formed under the cold conditions of winter as heat sinks in summer for space-cooling systems is being investigated.

An activity that is still largely an empirical art is the preparation of ice surfaces for recreational purposes such as figure skating, hockey, and curling. These surfaces are now made routinely to the exacting tolerances required for national and international competition. A related subject that is still imperfectly understood is the friction between ice and other materials. Motion of curling stones and the effect of sweeping on this motion, for example, have still not been explained satisfactorily. Perhaps the recreational aspects of ice are better left to art and speculation than to science and engineering.

Winter transportation has required giving attention to ice control on roads, railways, and aircraft runways. Electrical and other types of heating systems are used for situations where safety or economic factors justify the cost Sodium chloride is the least expensive chemical for effective ice control on roads for a relatively wide range of weather conditions, but it is not appropriate for areas used by aircraft, and the cost of the corrosion and environmental damage that has been caused by its use has not been properly evaluated. An example of this damage is the rapid deterioration of many concrete, multi-level automobile 
parking structures that has occurred in North America.

Many members of the International Glaciological Society participated in the advances in engineering that have been achieved in the past 50 years, and through them, the Society as well. It is appropriate to conclude this review by paying tribute to the role of the International Glaciological Society and its sister societies in the progress that has occurred. The literature clearly shows that it is the publications, symposia, and conferences of these societies that provide the most fertile ground for the creative interaction between the scientist and engineer, the individuals who have jointly achieved this progress.

\section{REFERENCES}

Arctic Ice Dynamics Joint Experiment. 1970-78. AIDJEX Bulletin, Nos. 1-40.

Ashton, G.D., ed. 1986. River and lake ice engineering. Littleton, CO, Water Resources Publications.

Barnes, H.T. 1928. Ice engineering. Montreal, Renouf Publishing Co.

Beskow, G. 1935. Soil freezing and frost heaving with special application to roads and railroads. Stockholm, Norstedt.

Brown, R.J.E. 1970. Permafrost in Canada; its influence on northern developments. Toronto, University of Toronto Press.

Canadian Standards Association. 1978. Design of highway bridges. Rexdale, Ontario, Canadian Standards Association.

Dorsey, N.E. 1940. Properties of ordinary water-substance in all its phases: water-vapor, water, and all the ices. New York, Reinhold Publishing Corporation.

Fish, A.M. 1982. Comparative analysis of the USSR construction codes and the US Army technical manual for design of foundations on permafrost. CRREL Report 82-14.

Goodwin, C.R., and others. 1985. Ice scour bibliography, by C.R. Goodwin, J.C. Finley, and L.M. Howard. Ottawa, Environmental Studies Revolving Funds. (Report 010.)

Gosudarstvennyy Komitet Soveta Ministrov SSSR po Delam Stroitel'stva. 1976. Stroitel'nyye normy $i$ pravila. Chast' 2. Proyektirovaniya. Glava 57. Nagruzki $i$ vozdeystviya na gidrotekhnicheskiye sooruzheniya (volnovyye, ledovyye $i$ ot sudov) [Construction standards and rules. Part 2. Design standards. Chapter 57. Loads exerted on hydraulic structures by waves, ice and ships]. Moscow, Stroyizdat. (SNiP 11-57-45.) [English translation: National Research Council of Canada. Technical Translation 1968, 1980.]

Gosudarstvennyy Komitet SSSR po Delam Stroitel'stva. 1983. Stroitel'nyye normy $i$ pravila. Nagruzki $i$ vozdeystviya na gidrotekhnicheskiye sooruzheniya (volnovyye, ledovyye $i$ ot sudov) [Construction standards and rules. Loads exerted on hydraulic structures by waves, ice and ships]. Moscow, Gosudarstvennyy Komitet SSSR po Delam Stroitel'stva. (SNiP 2.06.04-82.)

Howard, L.M., ed. 1986. Icebergs: a bibliography relevant to eastern Canadian waters. Ottawa, Environmental Studies Revolving Funds. (Report 030.)

Institut International du Froid. 1920-86. Bulletin de l'Institut International du Froid.

International Association for Hydraulic Research. 1959-86. Symposia proceedings. Montreal, Canada, 1959; Reykjavik, Iceland, 1970; Leningrad, U.S.S.R., 1972; Budapest, Hungary, 1974; Hanover, N.H., U.S.A., 1975; Lulea Sweden, 1978; Québec City, Canada, 1981; Hamburg, Germany, 1984; Iowa City, U.S.A., 1986.
International Glaciological Society. 1947-79. Glaciological literature. Journal of Glaciology, Vol. 1, No. 1 - Vol. 22, No. 88.

International Glaciological Society. 1980. Proceedings of the Conference on Use of Icebergs: Scientific and Practical Feasibility, Cambridge, UK, 1-3 April, 1980. Annals of Glaciology, Vol. 1.

International Permafrost Conference. 1963. Permafrost. International Conference 11-15 November, 1963, Lafayette, Indiana. Proceedings. Washington, DC, National Academy of Sciences. National Research Council. (Publication No. 1287.)

International Permafrost Conference. 1973. Permafrost. Second International Conference 13-28 July, 1973, Yakutsk. U.S.S.R. North American contribution. Washington, DC National Academy of Sciences.

International Permafrost Conference. 1978-79. Third International Conference on Permafrost, July 10-13, 1978 , Edmonton, Alberta. Canada. Proceedings. Vols, 1 and 2. Ottawa, National Research Council of Canada.

International Permafrost Conference. 1984. Permafrost. Fourth International Conference, July 17-22, 1983, Fairbanks, Alaska. Final proceedings. Washington, DC, National Academy Press.

International Symposium on Ground Freezing. 1980-81. Ground freezing. The 2nd International Symposium on Ground Freezing, Trondheim, June 24-26, 1980. Proceedings. Vols. I and 2. Trondheim, University of Trondheim. Norwegian Institute of Technology.

International Symposium on Ground Freezing. 1982. Proceedings of the Third International Symposium on Ground Freezing, 22-24 June, 1982 ... Hanover, New Hampshire, U.S.A. CRREL Special Report 82-16.

Jessberger, H.L., ed. 1979. Ground freezing. Proceedings of the First International Symposium on Ground Freezing, held in Bochum, March 8-10. 1978. Amsterdam, etc., Elsevier. (Developments in Geotechnical Engineering, Vol. 26.)

Johnston, G.H., ed. 1981. Permafrost: engineering design and construction. Toronto, etc., John Wiley and Sons.

Kinosita, S., and Fukuda, M., eds. 1985. Ground freezing. Proceedings of the Fourth International Symposium on Ground Freezing, Sapporo, 5-7 August, 1985. Rotterdam and Boston, A.A. Balkema.

Michel, B. 1984. Comparison of field data with theories on ice cover progression in large rivers. Canadian Journal of Civil Engineering, Vol. 11, No. 4, p. 789-814.

Minsk, L.D., ed. 1983. Atmospheric Icing of Structures. Proceedings of First International Workshop, 1-3 June, 1982, Hanover, New Hampshire. CRREL Special Report 83-17.

POAC. 1971-85. Proceedings. International conferences on port and ocean engineering under Arctic conditions: Trondheim, Norway, 1971; Reykjavik, Iceland, 1973; Fairbanks, Alaska, U.S.A., 1975; St. John's, Newfoundland, Canada, 1977; Trondheim, Norway, 1979; Québec City, Canada, 1981; Helsinki, Finland, 1983; Narssarssuaq, Greenland, 1985

Sanger, F.J., ed. 1978. Permafrost. Second International Conference, July 13-28, 1973. USSR contribution. Washington, DC, National Academy of Sciences.

Scott Polar Research Institute. 1980-86. Recent Polar and Glaciological Literature.

SNiP 76. 1977. Subsoils and foundations on permafrost. Design codes. Moscow, Stroyizdat. (SNiP II-18-76.)

Starosolszky, Ö., ed. 1977. Multilingual ice terminology. Budapest, Research Centre for Water Resources. 